Cilt/Volume:12 Sayı/Issue:1 Ocak/January 2020

Araştırma Makalesi / Research Article

\title{
Artificial Neural Network Modeling of The Removal of Cr (VI) on by Polymeric Calix[6]arene in Aqueous Solutions
}

\author{
Abdullah Erdal Tümer ${ }^{1,2}$ iD \\ ${ }^{1}$ 1Necmettin Erbakan Üniversitesi,Mühendislik Mimarlık Fakültesi, Bilgisayar Mühendisliği, 42195,Konya,TÜRKIYE \\ ${ }^{2}$ Kyrgyz - Turkish Manas University, KYRGYZSTAN \\ Başvuru/Received: 19/10/2018 \\ Kabul / Accepted: 06/08/2019 \\ Çevrimiçi Basım / Published Online: 27/09/2019 \\ Son Versiyon/Final Version: 31/01/2020

\begin{abstract}
The artificial neural network-based model was developed to predict the sorption capacity and removal efficiency of calixarene for $\mathrm{Cr}(\mathrm{VI})$ in aqueous solutions. The input variables were initial concentration of $\mathrm{Cr}(\mathrm{VI})$, adsorbent dosage, contact time, and $\mathrm{pH}$, while the sorption capacity and the removal efficiency were considered as output. They have been used for the training and simulation of the network in the current work. The training results were tested using the input data (simulated data) that were not shown to the network. According to the indicator, the optimum and most reliable model was found based on the test results
\end{abstract}

Key Words

“Artificial Neural Network; Modeling; Sorption; Removal Efficiency; Sorption Capacity” 


\section{Introduction}

Artificial neural network is an algorithm that uses computing technique inspired by human brain that has its origin in (McCulloch $\&$ Pitts, 1943). ANNs have been applied successfully to broad spectrum of application field on several sciences, in complex systems such as pattern recognition (Gao, Liang, Chen, \& Xu, 2015; Köhler, Bock, Hornegger, \& Michelson, 2015), dynamic modeling of process operation (Azarpour, Alwi, Zahedi, Madooli, \& Millar, 2015), process control and prediction (Chairez, García-Peña, \& Cabrera, 2009; Lertworasirikul \& Tipsuwan, 2008), parameter estimation for the design of controllers (Bounar, Boulkroune, Boudjema, \& Farza, 2015), fault diagnosis of processes (Li, Zhu, Jiang, Zhou, \& Chen, 2015), and time series forecasting (Voyant, Nivet, Paoli, Muselli, \& Notton, 2015). ANNs have recently been used to model the results obtained in experiments for environmental research studies in particular, such as wastewater treatment processes (Aber, Amani-Ghadim, \& Mirzajani, 2009; Amani-Ghadim \& Dorraji, 2015; Dutta, Parsons, Bhattacharjee, Bandhyopadhyay, \& Datta, 2010; Ghaedi, Ghaedi, \& Karami, 2015; Halder, Dhawane, Barai, \& Das, 2015; Todoran, Todoran, \& Szakacs, 2016; Tomczak, 2011). ANNs can represent the input and output data of various experimental studies as an approximate mathematical function. Artificial neural network architecture has three layers called input layer, hidden layer and output layer.

Method of training the ANN explains the input-output relation for the modeled system using datasets (Sato, Sha, \& Palosaari, 1999). The main advantage provided by an ANN model over traditional methods (such as multi linear regression) is that they do not need the complex underlying characteristics of any physical process (Nayak, Rao, \& Sudheer, 2006).

In this study, feedforward backpropagation type of artificial neural network model was developed to predict the sorption capacity and removal efficiency of polymer supported calixarenes for $\mathrm{Cr}$ (VI) in aqueous solutions. A sorption process requires costly equipment, expertise and time. The most important jobs in the sorption process are modeling and optimization to the process performance at the lowest cost (Khandanlou et al., 2016). One way of low cost modeling is the use of artificial neural networks. In addition, both ANNs have been used for modeling of sorption process in many studies (Babaei et al., 2016; Heibati et al., 2016; Kooh, Dahri, Lim, Lim, \& Malik, 2016; Mahmoodi et al., 2016; Mahmoodi, Hosseinabadi - Farahani, \& Chamani, 2017; Yurtsever, Yurtsever, Şengil, \& Kıratlı Yılmazçoban, 2015) and ANN models have provided reliable and powerful results.

On the other hand, the used polymer supported calixarenes in this study is limited in adsorption process. However, when the related literature is taken into consideration, it can be observed that there have been no reports of ANN modeling of adsorption process carried out with polymeric calixarenes. For the first time in this study, modeling of polymer supported calixerene in sorption process was carried out through ANN method. The ANN model was created by considering 19 different sorption experiment parameters, and the percentages of removal efficiency and sorption capacity dependent on these parameters. The model was the initial time trained using 15 experimental datasets, which were then compared with other 4 experimental data (the used simulated data) to test the model.

Nowadays, the water pollution is an important issue because of the existence of toxic heavy metals in wastewaters produced by industrial resources (F. Fu \& Wang, 2011). Chromium (Cr) has a remarkably lot among these toxic heavy metals in wastewater releasing from industry. $\mathrm{Cr}$ (VI) is a toxic cation because it passes as $\mathrm{HCr} 2 \mathrm{O} 7$ - or $\mathrm{Cr} 2 \mathrm{O} 72$ - to cell membranes and damages biological molecules via oxidation. Therefore, interaction with $\mathrm{Cr}$ (VI) species can cause various health troubles, such as ulcer disease, skin irritation, pulmonary congestion and liver damage (Sengupta \& Clifford, 1986; Zhao, SenGupta, \& Stewart, 1998). Thus, the purification of wastewaters with $\mathrm{Cr}$ (VI) prior to release is a necessary operation. Various techniques, such as precipitation, solvent extraction, electrochemical purification, evaporation and membrane filtration have been used to purify $\mathrm{Cr}$ (VI) pollutants from aqueous media. However, these methods fail to remove them in small concentrations. Thus, among them adsorption is one of the important methods to solve this problem. In the literature, different adsorbents have been used for the removal of Cr (VI) (Sengupta \& Clifford, 1986; Zhao et al., 1998). Supramolecular compounds are versatile tools in host-guest chemistry for the production of many host molecules recognizing the neutral or charged guests. Calix[n]arenes composed of phenolic units with linked methylene bridges are such supramolecular compounds and are very well-known as effective and attractive host molecules (Asfari, Böhmer, Harrowfield, \& Vicens, 2007; Gutsche, 2008). In a previous work, the preparation and $\mathrm{Cr}$ (VI) sorption properties of aminopropyl silica gel-immobilized calix[6]arene polymer (C[6]APS) were studied and the optimum parameters (initial concentration, adsorbent dosage, contact time and $\mathrm{pH}$ ) belong to $\mathrm{Cr}(\mathrm{VI})$ were determined at $25^{\circ} \mathrm{C}$. Although the sorption efficiency and removal capacity of C[6]APS for $\mathrm{Cr}(\mathrm{VI})$ has been determined with experimental studies, developing an ANN model for prior estimation of them is important. Thus, based on this experimental dataset, an ANN model was developed in the current study. Furthermore, another innovation in this study is the use of polymeric calixarenes has been modeled through ANN for the first time in the process of adsorption. The results showed that this ANN model could be used to as a considerable performance evaluation tool for the removal efficiency and sorption capacity of C[6]APS for $\mathrm{Cr}(\mathrm{VI})$.

\section{Definition of ANN}

The simplest definition of ANN is a computer simulation originated from biological nervous system (Kang \& Yoon, 1994). ANNs learn from example, whereby that existing dataset of input patterns and corresponding output patterns is presented to find out the norms that determine the relationship between the patterns (Heaton, 2008). 
This structure consists of three components: nodes (neurons); connections (weights); and training algorithms. Neurons are also called processing elements which communicate by sending signals to many other neurons in the following layer working in parallel to solve a specific problem, thus resulting in various types of ANNs (R.-Q. Fu, Xu, \& Pan, 2005). One of the most popular ANNs is the feedforward backpropagation algorithm developed by (Rumelhart, Hinton, \& Williams, 1985). The term "feedforward", describes how this neural network processes and recalls patterns. The term "backpropagation" is described due to the error back propagation modify the network. Backpropagation is a method of training a network. When using the approach, both sample inputs and predicted outputs must be provided to the network (Self, 1988).

A three-layer network model, consisting of 4 neurons in the input layer (contact time, adsorbent dosage, pH, and initial concentration), two hidden layers with 4,5,6,7 neurons respectively, and an output layer with1 neurons (removal efficiency or sorption capacity) is developed in this study, as shown in Fig. 1.

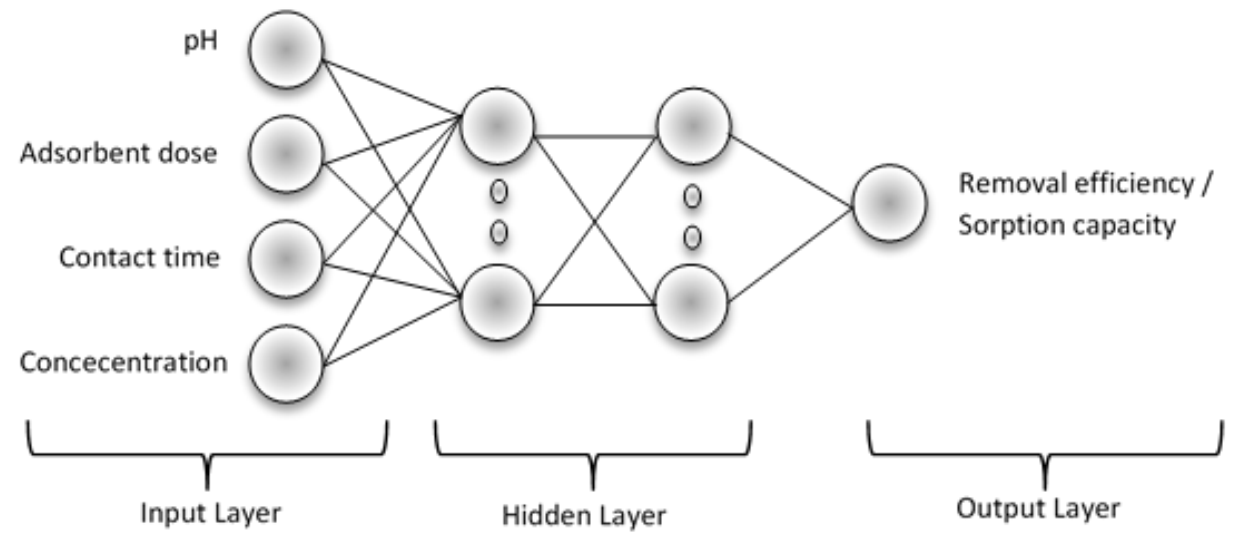

Figure 1. Configuration of ANN

Selecting the appropriate network type and transfer function are crucial tasks for designing a neural network model. In contrast, the qualities of output performance result will unreliable (Dutta et al., 2010). The present work a feedforward backpropagation algorithm was developed. Traincgp was used as a training function. Three transfer functions (tansig, purelin and logsig) were applied for the hidden layer. Table 1 shows the algorithms of altered transfer functions. To construct the ANN model, MATLAB software was used. Adaptability is specified by the number of hidden neurons so the hidden of number neurons are very important in the training process of the ANNs. On the other hand, excessive neurons may result in overfitting in the hidden layer (Self, 1988). So altered numbers of neurons $(4,5,6,7)$ were performed to select the best training algorithm.

Table 1. Transfer functions used in algorithms

\begin{tabular}{ll}
\hline Transfer function & Algorithm \\
\hline Tansig & $\operatorname{tansig}(n)=2 /(1+\exp (-2 n))-1$ \\
Purelin & purelin $(n)=n$, for all $n$ \\
Logsig & $\operatorname{logsig}(n)=1(1+\exp (-n))$ \\
\hline
\end{tabular}

Mean absolute error (MAE), root mean square error (RMSE) and coefficient of determination ( $\mathrm{R}^{2}$ ) were used in ANN model to assess the best feedforward backpropagation algorithm. The formulas for calculation of, MAE, RMSE and $\mathrm{R}^{2}$ are:

$$
\begin{aligned}
& M A E=\frac{1}{n} \sum_{i=1}^{n}\left|Y_{a, i}-Y_{p, i}\right| \\
& R M S E=\sqrt{\frac{1}{n}} \sum_{i=1}^{n}\left(Y_{a, i}-Y_{p, i}\right)^{2} \\
& R^{2}=1-\frac{\sum_{1}^{n}\left(Y_{p, i}-Y_{a, i}\right) 2}{\sum_{i=1}^{n}\left(Y_{a, i}-Y_{m}\right) 2}
\end{aligned}
$$

Where $\mathrm{n}$ is the number of points, $\mathrm{Y}_{\mathrm{a}, \mathrm{i}}$ is the actual value, $\mathrm{Y}_{\mathrm{m}}$ is the mean of actual value and $\mathrm{Y}_{\mathrm{p}, \mathrm{i}}$ is the predicted value.

\section{Experimental Description}

Preparation of C[6]APS as an adsorbent material and its sorption studies for Cr(VI) are described in a previous study (Tabakci, 2008). The synthetic route for C[6]APS is illustrated in Fig. 2. 


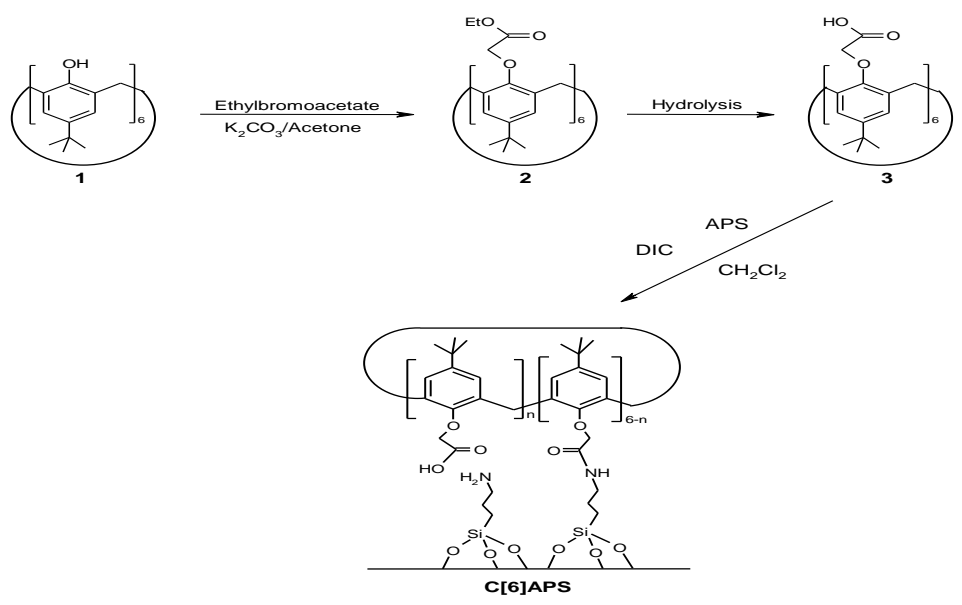

Figure 2. Synthetic route of preparation of C[6]APS

\section{Result and Discussion}

Two methods are used to determine the number of sorption experiments. The first one is the total number of experiments determined by the expert. The second is the continuation of the experiment until achieving the optimum parameters of the sorption parameters, which provide maximum removal. In this study, experiments were not continued, since optimum results were reached in 19 experiments. Nineteen experimental datasets were used to develop the ANN model, with feedforward backpropagation algorithm, to predict the sorption capacity and removal efficiency of C[6]APS for $\mathrm{Cr}(\mathrm{VI})$. The data-set was divided into two subsets training and simulating that contained 15 and 4 samples. The training and simulating subsets of the proportion were 73-27\%, respectively. The training data-set was divided into three subsets (training 70\%, testing $15 \%$ and validation 15\%). The ranges of dataset parameters and their related statistic are presented in Table 2.

Table 2. Ranges of data set and their statistic

\begin{tabular}{|c|c|c|c|}
\hline \multirow[t]{2}{*}{ Parameters } & \multicolumn{2}{|c|}{ Data Statistic } & \multirow[b]{2}{*}{ Unit } \\
\hline & Ranges & Mean \pm S.D. & \\
\hline \multicolumn{4}{|l|}{ Input Layer } \\
\hline Adsorbent Dosage & $25,00-100,0$ & $32,89 \pm 20,50$ & $\mathrm{Mg}$ \\
\hline Concentration & $10,40-41,6$ & $13,68 \pm 8,52$ & Ppm \\
\hline $\mathrm{pH}$ & $1,50-7,5$ & $2,29 \pm 1,75$ & \\
\hline Contact Time & $30,00-180,0$ & $74,21 \pm 36,56$ & Min \\
\hline \multicolumn{4}{|l|}{ Output Layer } \\
\hline Removal Efficiency & $13,60-83,80$ & $63,54 \pm 25,29$ & $\%$ \\
\hline Sorption Capacity & $0,08-11,49$ & $3,23 \pm 2,89$ & $\mathrm{mg} / \mathrm{g}$ \\
\hline
\end{tabular}

\subsection{Optimization of Network}

One of the most important points in designing an ANN model is the choice of suitable and fitting parameters. The chosen training, and transfer functions, and network type may not be suitable for an optimized model. The suitable training algorithm in different layers, the number of hidden layers, the number of neurons, the determination of the transfer and training functions are highly responsive parameters in the design of ANNs. The training results of the ANN model should be compared with the simulated data that were not shown to the network for testing purposes. If the training results do not agree with the simulated results, it will not be possible to develop a suitable model for removal efficiency and sorption capacity. Several parameters were used with different correlations through trial and error, in order to find the best ANN model. Models were designed to generate the minimum mean absolute error (MAE) and root mean square error (RMSE), and the maximum coefficient of determination $\left(\mathrm{R}^{2}\right)$ (measures the model performance) values, with 4-7 neurons in hidden layers, and tansig, logsig, and purelin transfer functions. Also the maximum number of epochs were selected as 500. Network training data and simulated data were compared, in order to confirm the designed models.

\subsection{Removal efficiency modeling with ANNs}

In this presented work, a feedforward backpropagain network was constructed as network type. Many different transfer functions (logsig, tansig, and purelin) were used in the hidden layer, and the output transfer function "purelin" was used in the output layer. The Learngdm (used to calculate weight and bias learning function) function was used as the adaption learning function, and MAE and RMSE and $\mathrm{R}^{2}$ were determined as the performance function. In Table 3, the network models were repeated with different neurons and transfer functions, and comparative results with simulated values, the coefficient of determination $\left(\mathrm{R}^{2}\right)$ belonging to these results, and MAE and RMSE values, are presented. 
The model with the optimum performance was reached by changing the number of neurons in the hidden layer and the transfer functions. In Table 3, it can be seen that the most satisfactory results for feedforward backpropagation artificial neural network belong to the model in which the hidden layer has 5 neurons, and the transfer function is logsig. Similarly, Fig. 3 shows the network model tested using the simulated data that were not shown to the network.

Table 3. Results of ANN model for removal efficiency.

\begin{tabular}{ccccccc}
\hline $\begin{array}{c}\text { Number of } \\
\text { neuron }\end{array}$ & $\begin{array}{c}\text { Transfer } \\
\text { function }\end{array}$ & $\begin{array}{c}\text { Train } \\
\left(\mathrm{R}^{2}\right)\end{array}$ & $\begin{array}{c}\text { Validation } \\
\left(\mathrm{R}^{2}\right)\end{array}$ & $\begin{array}{c}\text { Test } \\
\left(\mathrm{R}^{2}\right)\end{array}$ & RMSE & MAE \\
\hline \multirow{3}{*}{4} & Logsig & 0,97 & 0,98 & 0,46 & $6,48 \times 10-5$ & 0,05720 \\
& Tansig & 0,99 & 0,99 & 0,43 & $6,04 \times 10-4$ & 56,3431 \\
& Purelin & 0,99 & 0,99 & 0,46 & $1,64 \times 10-2$ & 0,04280 \\
& Logsig & $\mathbf{0 , 9 9}$ & $\mathbf{0 , 9 9}$ & $\mathbf{0 , 8 9}$ & $\mathbf{9 , 2 8 \times 1 0 - 4}$ & $\mathbf{0 , 0 3 7 8 7}$ \\
5 & Tansig & 0,99 & 0,99 & 0,10 & $7,40 \times 10-4$ & 0,10076 \\
& Purelin & 0,99 & 0,99 & 0,48 & $1,49 \times 10-5$ & 0,02949 \\
& Logsig & 0,99 & 0,98 & 0,34 & $9,30 \times 10-5$ & 0,03951 \\
6 & Tansig & 0,99 & 0,99 & 0,45 & $7,43 \times 10-4$ & 0,04296 \\
& Purelin & 0,93 & 0,99 & 0,47 & $1,25 \times 10-3$ & 9,43880 \\
& Logsig & 0,99 & 0,75 & 0,46 & $3,29 \times 10-3$ & 0,08710 \\
7 & Tansig & 0,99 & 0,99 & 0,43 & $1,25 \times 10-3$ & 0,04375 \\
& purelin & 0,83 & 0,98 & 0,45 & $1,80 \times 10-2$ & 0,03824 \\
\hline
\end{tabular}

$\multimap$ Experimental Data $\quad \longrightarrow$ Simulated Data

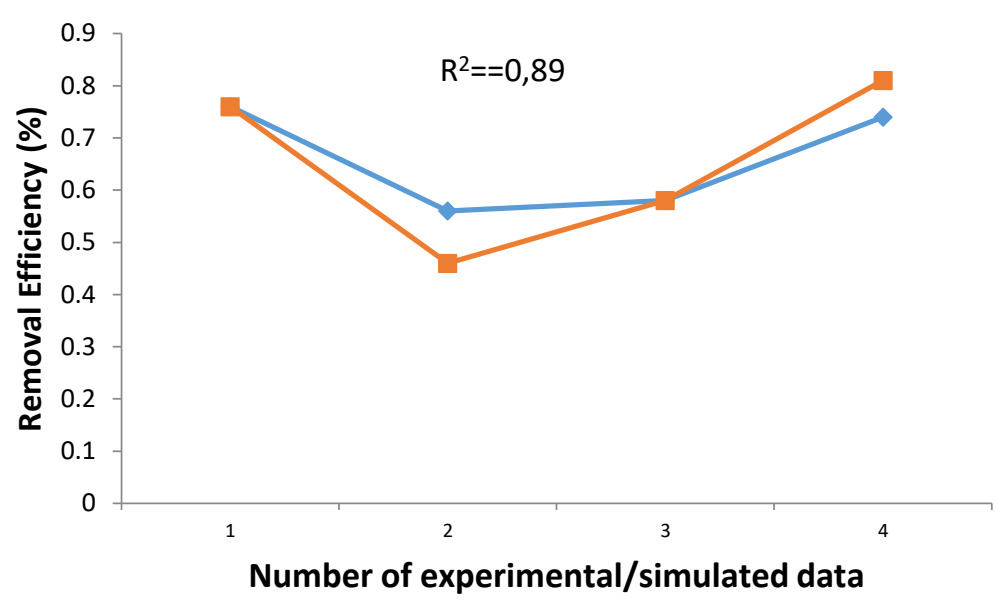

Figure 3. Simulated data and experimental data for removal efficiency

\subsection{Sorption capacity modeling with ANNs}

In Table 4, the results of the artificial neural network model, developed with different correlations for sorption capacity are shown.

Table 4. Results of neural network for prediction of sorption capacity.

\begin{tabular}{ccccccc}
\hline $\begin{array}{c}\text { Number of } \\
\text { neuron }\end{array}$ & $\begin{array}{c}\text { Transfer } \\
\text { function }\end{array}$ & $\begin{array}{c}\text { Train } \\
\left(\mathrm{R}^{2}\right)\end{array}$ & $\begin{array}{c}\text { Validation } \\
\left(\mathrm{R}^{2}\right)\end{array}$ & $\begin{array}{c}\text { Test } \\
\left(\mathrm{R}^{2}\right)\end{array}$ & RMSE & MAE \\
\hline \multirow{3}{*}{4} & logsig & 0,99 & 0,99 & 0,39 & $2,23 \times 10-2$ & 0,03558 \\
& tansig & 0,99 & 0,98 & 0,23 & $3,10 \times 10-2$ & 0,02590 \\
& purelin & 0,99 & 0,99 & 0,39 & $2,49 \times 10-1$ & 0,18980 \\
& logsig & 0,75 & 0,62 & 0,77 & $1,51 \times 10-1$ & 0,11220 \\
5 & tansig & $\mathbf{0 , 9 8}$ & $\mathbf{0 , 9 9}$ & $\mathbf{0 , 9 9}$ & $\mathbf{3 , 0 7 \times 1 0 - 6}$ & $\mathbf{0 , 0 1 0 1 5}$ \\
& purelin & 0,99 & 0,99 & 0,58 & $2,66 \times 10-3$ & 0,02684 \\
& logsig & 0,98 & 0,75 & 0,40 & $5,57 \times 10-2$ & 0,22100 \\
6 & tansig & 0,98 & 0,99 & 0,46 & $2,70 \times 10-4$ & 0,04343 \\
& purelin & 0,93 & 0,99 & 0,59 & $2,45 \times 10-2$ & 0,03670 \\
& logsig & 0,93 & 0,63 & 0,86 & $9,01 \times 10-1$ & 0,85900 \\
7 & tansig & 0,95 & 0,99 & 0,55 & $2,33 \times 10-3$ & 0,04267 \\
& purelin & 0,99 & 0,68 & 0,54 & $3,11 \times 10-1$ & 0,28060 \\
\hline
\end{tabular}


The model yielded more satisfactory results compared to removal efficiency. The $\mathrm{R}^{2}$ values were found to be within the range of 0.10-0.89 for removal efficiency, whereas in the model belonging to sorption capacity, $\mathrm{R}^{2}$ values were within the range of 0.23 0.99. The number of neurons in the optimum model was found to be 5 , which was equal to the number of neurons in removal efficiency. However, the training function was determined as tansig. The MSE value was also found to be substantially lower compared to removal efficiency. The graph of the values produced by the network trained with the simulated values of the sorption capacity and the coefficient of determination, which was found as $\mathrm{R}^{2}=0.99$, are shown in Fig. 4.

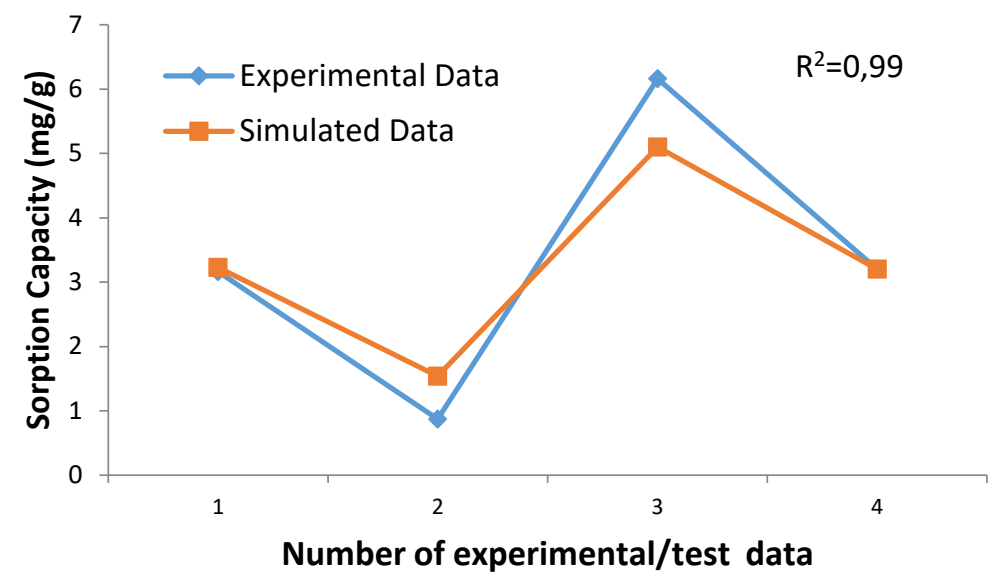

Figure 4. Simulated data and experimental data for Sorption Capacity

The increase of the coefficient of determination to 0.99 shows that the sorption capacity can be determined at a rate of $99 \%$ with contact time, $\mathrm{pH}$, initial concentration data and adsorbent dosage.

\section{Conclusion}

This study indicates that the Cr (VI) removal efficiency and sorption capacity of C[6]APS (polymer supported calixarenes) can be confidently modeled using the ANN technique. Although there have been many studies about using different adsorbents for the removal of $\mathrm{Cr}$ (VI) and modeling with ANN, there have been no studies about the use of polymeric calixarens in an adsorption process modeled through ANN. Hence in this study is the use of polymeric calixarenes has been modeled through ANN for the first time in the process of adsorption. Before using the developed ANN model in a real sorption estimation, the training results should not be considered as sufficient, and should certainly be tested using the simulated values that are not shown to the network. It is necessary to have a high consistency between the simulated results and the experimental results, in order to obtain a satisfactory level of removal efficiency or sorption capacity. With this aim, experiments were conducted using different neuron numbers and transfer functions, to find the appropriate model. It was found that it would be appropriate to use the logsig transfer function with 5 neurons to estimate the most suitable removal efficiency, and to use the tansig transfer function with 5 neurons to estimate the sorption capacity. It was shown that the developed ANN models can be used in an efficient way and as a tool to predict in the computer-based removal efficiency and sorption capacity processes.

\section{Acknowledgment}

I thank Prof. Dr. Mustafa TABAKÇI for assistance and comments that greatly improved the manuscript.

\section{References}

Aber, S., Amani-Ghadim, A., \& Mirzajani, V. (2009). Removal of Cr (VI) from polluted solutions by electrocoagulation: Modeling of experimental results using artificial neural network. Journal of hazardous materials, 171(1-3), 484-490.

Amani-Ghadim, A., \& Dorraji, M. S. (2015). Modeling of photocatalyatic process on synthesized ZnO nanoparticles: Kinetic model development and artificial neural networks. Applied Catalysis B: Environmental, 163, 539-546.

Asfari, M.-Z., Böhmer, V., Harrowfield, J., \& Vicens, J. (2007). Calixarenes 2001: Springer Science \& Business Media.

Azarpour, A., Alwi, S. R. W., Zahedi, G., Madooli, M., \& Millar, G. J. (2015). Catalytic activity evaluation of industrial Pd/C catalyst via gray-box dynamic modeling and simulation of hydropurification reactor. Applied Catalysis A: General, 489, $262-271$.

Babaei, A. A., Khataee, A., Ahmadpour, E., Sheydaei, M., Kakavandi, B., \& Alaee, Z. (2016). Optimization of cationic dye adsorption on activated spent tea: equilibrium, kinetics, thermodynamic and artificial neural network modeling. Korean journal of chemical engineering, 33(4), 1352-1361. 
Bounar, N., Boulkroune, A., Boudjema, F., \& Farza, M. (2015). Adaptive fuzzy vector control for a doubly-fed induction motor. Neurocomputing, 151, 756-769.

Chairez, I., García-Peña, I., \& Cabrera, A. (2009). Dynamic numerical reconstruction of a fungal biofiltration system using differential neural network. Journal of Process Control, 19(7), 1103-1110.

Dutta, S., Parsons, S. A., Bhattacharjee, C., Bandhyopadhyay, S., \& Datta, S. (2010). Development of an artificial neural network model for adsorption and photocatalysis of reactive dye on TiO2 surface. Expert Systems with Applications, 37(12), 8634-8638.

Fu, F., \& Wang, Q. (2011). Removal of heavy metal ions from wastewaters: a review. Journal of environmental management, 92(3), 407-418.

Fu, R.-Q., Xu, T.-W., \& Pan, Z.-X. (2005). Modelling of the adsorption of bovine serum albumin on porous polyethylene membrane by back-propagation artificial neural network. Journal of membrane science, 251(1-2), 137-144.

Gao, H., Liang, L., Chen, X., \& Xu, G. (2015). Feature extraction and recognition for rolling element bearing fault utilizing shorttime Fourier transform and non-negative matrix factorization. Chinese Journal of Mechanical Engineering, 28(1), 96-105.

Ghaedi, A., Ghaedi, M., \& Karami, P. (2015). Comparison of ultrasonic with stirrer performance for removal of sunset yellow (SY) by activated carbon prepared from wood of orange tree: Artificial neural network modeling. Spectrochimica Acta Part A: Molecular and Biomolecular Spectroscopy, 138, 789-799.

Gutsche, C. D. (2008). Calixarenes: an introduction: Royal Society of Chemistry.

Halder, G., Dhawane, S., Barai, P. K., \& Das, A. (2015). Optimizing chromium (VI) adsorption onto superheated steam activated granular carbon through response surface methodology and artificial neural network. Environmental Progress \& Sustainable Energy, 34(3), 638-647.

Heaton, J. (2008). Introduction to neural networks with Java: Heaton Research, Inc.

Heibati, B., Rodriguez-Couto, S., Ozgonenel, O., Turan, N. G., Aluigi, A., Zazouli, M. A., .. . Albadarin, A. B. (2016). A modeling study by artificial neural network on ethidium bromide adsorption optimization using natural pumice and iron-coated pumice. Desalination and Water Treatment, 57(29), 13472-13483.

Kang, H. T., \& Yoon, C. J. (1994). Neural network approaches to aid simple truss design problems. Computer-Aided Civil and Infrastructure Engineering, 9(3), 211-218.

Khandanlou, R., Masoumi, H. R. F., Ahmad, M. B., Shameli, K., Basri, M., \& Kalantari, K. (2016). Enhancement of heavy metals sorption via nanocomposites of rice straw and $\mathrm{Fe} 3 \mathrm{O} 4$ nanoparticles using artificial neural network (ANN). Ecological Engineering, 91, 249-256.

Kooh, M. R. R., Dahri, M. K., Lim, L. B., Lim, L. H., \& Malik, O. A. (2016). Batch adsorption studies of the removal of methyl violet 2B by soya bean waste: isotherm, kinetics and artificial neural network modelling. Environmental Earth Sciences, 75(9), 783.

Köhler, T., Bock, R., Hornegger, J., \& Michelson, G. (2015). Computer-aided diagnostics and pattern recognition: Automated glaucoma detection Teleophthalmology in Preventive Medicine (pp. 93-104): Springer.

Lertworasirikul, S., \& Tipsuwan, Y. (2008). Moisture content and water activity prediction of semi-finished cassava crackers from drying process with artificial neural network. Journal of food Engineering, 84(1), 65-74.

Li, W., Zhu, Z., Jiang, F., Zhou, G., \& Chen, G. (2015). Fault diagnosis of rotating machinery with a novel statistical feature extraction and evaluation method. Mechanical Systems and Signal Processing, 50, 414-426.

Mahmoodi, N. M., Hosseinabadi-Farahani, Z., Bagherpour, F., Khoshrou, M. R., Chamani, H., \& Forouzeshfar, F. (2016). Synthesis of $\mathrm{CuO}-\mathrm{NiO}$ nanocomposite and dye adsorption modeling using artificial neural network. Desalination and Water Treatment, 57(37), 17220-17229.

Mahmoodi, N. M., Hosseinabadi-Farahani, Z., \& Chamani, H. (2017). Dye adsorption from single and binary systems using NiO$\mathrm{MnO} 2$ nanocomposite and artificial neural network modeling. Environmental Progress \& Sustainable Energy, 36(1), 111-119.

McCulloch, W. S., \& Pitts, W. (1943). A logical calculus of the ideas immanent in nervous activity. The bulletin of mathematical biophysics, 5(4), 115-133. 
Nayak, P. C., Rao, Y. S., \& Sudheer, K. (2006). Groundwater level forecasting in a shallow aquifer using artificial neural network approach. Water resources management, 20(1), 77-90.

Rumelhart, D. E., Hinton, G. E., \& Williams, R. J. (1985). Learning internal representations by error propagation. Retrieved from

Sato, A., Sha, Z., \& Palosaari, S. (1999). Neural networks for chemical engineering unit operations. Chemical Engineering \& Technology: Industrial Chemistry-Plant Equipment-Process Engineering-Biotechnology, 22(9), 732-739.

Self, J. (1988). Artificial intelligence and human learning: intelligent computer-aided instruction: Chapman and Hall London.

Sengupta, A. K., \& Clifford, D. (1986). Important process variables in chromate ion exchange. Environmental science \& technology, 20(2), 149-155.

Tabakci, M. (2008). Immobilization of calix [6] arene bearing carboxylic acid and amide groups on aminopropyl silica gel and its sorption properties for Cr (VI). Journal of Inclusion Phenomena and Macrocyclic Chemistry, 61(1-2), 53-60.

Todoran, R., Todoran, D., \& Szakacs, Z. (2016). Optical luminescence studies of the ethyl xanthate adsorption layer on the surface of sphalerite minerals. Spectrochimica Acta Part A: Molecular and Biomolecular Spectroscopy, 152, 591-595.

Tomczak, E. (2011). Application of ANN and EA for description of metal ions sorption on chitosan foamed structure-Equilibrium and dynamics of packed column. Computers \& chemical engineering, 35(2), 226-235.

Voyant, C., Nivet, M.-L., Paoli, C., Muselli, M., \& Notton, G. (2015). Heterogeneous transfer functions multi-layer perceptron (MLP) for meteorological time series forecasting. International Journal of Modeling, Simulation, and Scientific Computing, 6(02), 1550013.

Yurtsever, U., Yurtsever, M., Şengil, İ. A., \& Kıratlı Yılmazçoban, N. (2015). Fast artificial neural network (FANN) modeling of Cd (II) ions removal by valonia resin. Desalination and Water Treatment, 56(1), 83-96.

Zhao, D., SenGupta, A. K., \& Stewart, L. (1998). Selective removal of Cr (VI) oxyanions with a new anion exchanger. Industrial \& engineering chemistry research, 37(11), 4383-4387. 